\title{
S8.5
}

\section{LE ENCEFALOPATIE SPONGIFORMI TRASMISSIBILI}

\section{Pocchiari M.}

Istituto Superiore di Sanità, Roma

Le encefalopatie spongiformi trasmissibili (EST), malattie neurodegenerative ad esito fatale dell'uomo (malattia di Creutzfeldt-Jakob, MCJ, sindrome di Gerstmann-Sträussler-Scheinker, ed insonnia fatale sporadica o familiare) e degli animali (scrapie della pecora e capra, encefalopatia spongiforme bovina, BSE) sono causate da agenti infettivi non convenzionali chiamati prioni. Il prione ha dimensioni più piccole dei virus ed è incredibilmente resistente alle procedure impiegate per rimuovere o inattivare altri microrganismi noti. Metodi fisici (calore) e metodi chimici (fenolo, cloroformio, formaldeide ed alcoli) sono inefficaci; una riduzione della carica infettiva si ottiene solo con un prolungato trattamento in autoclave o con procedure capaci di idrolizzare le proteine. Non è possibile identificare alcun acido nucleico associato con il prione. Il termine prione deriva dall'inglese "prion" (da proteina infetta) ed è stato coniato per sottolineare l'ipotesi che l'agente infettivo sia composto solo da proteine, senza la presenza di acidi nucleici.

Nei tessuti infetti da EST è presente una proteina anomala, la Proteina Prionica patologica o $\operatorname{PrP}^{\mathrm{EST}}$, che deriva da un'alterata struttura tridimensionale della Proteina Prionica cellulare $\left(\mathrm{PrP}^{\mathrm{c}}\right)$. Nei soggetti infetti la $\operatorname{PrP}^{\mathrm{c}}$ assume una conformazione spaziale alterata che consiste nella trasformazione di alcune strutture alfaelica in strutture a foglietti beta.

Come per altri agenti microbici, esistono vari ceppi di prioni: sono stati isolati circa venti ceppi di scrapie, uno o forse due di BSE, ed almeno tre distinti ceppi associati alla MCJ.

Lo studio di queste patologie si avvale di modelli animali, transgenici e non transgenici. I topi transgenici sono ottenuti mediante l'introduzione nel topo di una o più copie del gene della $\operatorname{PrP}^{\mathrm{c}}$ di una specie diversa. Tra i modelli animali non transgenici quello rappresentato 
da un roditore selvatico, l'arvicola rossastra (Clethrionomys glareolus) potrebbe fornire un nuovo e potente strumento di studio e di prevenzione in quanto permette di discriminare diversi ceppi di prioni delle EST naturali con una elevata efficienza di infezione e tempi di incubazione paragonabili o addirittura inferiori a quelli dei topi transgenici.

L'organo bersaglio del prione è il sistema nervoso centrale, dove si osservano caratteristiche lesioni degenerative. Al contrario di altri microrganismi, il prione non stimola invece l'attivazione di cellule infiammatorie nei tessuti infetti.

In seguito ad infezione per via l'agente si diffonde nell'organismo per via ematica dando inizio ad una prima fase replicativa nelle cellule follicolari dendritiche dei tessuti linfatici. Dagli organi linfatici attraverso i nervi periferici, mediante il trasporto assonale, il prione raggiunge il midollo spinale e quindi l'encefalo dove continua a replicarsi provocando la formazione di $\operatorname{PrP}^{\mathrm{EST}} \mathrm{e}$ le tipiche lesioni neuropatologiche, quindi l'insorgenza dei sintomi clinici e la morte dell'animale. 